\title{
Purification of xyloglucan endotransglycosylases (XETs): a generally applicable and simple method based on reversible formation of an enzyme-substrate complex
}

\author{
Nancy M. STEELE and Stephen C. FRY ${ }^{1}$ \\ The Edinburgh Cell Wall Group, Institute of Cell and Molecular Biology, The University of Edinburgh, Daniel Rutherford Building, The King's Buildings, Mayfield Road, \\ Edinburgh EH9 3JH, U.K.
}

\begin{abstract}
We describe a novel and general, mechanism-based, method for purification of xyloglucan endotransglycosylases (XETs) from crude plant extracts. Putative isoforms, obtained by step-wise precipitation with $\left(\mathrm{NH}_{4}\right)_{2} \mathrm{SO}_{4}$, were incubated with tamarind xyloglucan $(\approx 1 \mathrm{MDa})$ to form stable xyloglucan-XET complexes with apparent molecular masses $>500 \mathrm{kDa}$ on gelpermeation chromatography (GPC). Subsequent addition of xyloglucan-derived oligosaccharides (a mixture of XET acceptor substrates) caused a shift in the GPC elution volume of the
\end{abstract}

activity back to that expected of $\mathrm{a} \approx 32 \mathrm{kDa}$ protein, presumably by completing the transglycosylation reaction and so freeing the enzyme from the xyloglucan (donor substrate). This simple twostep method enabled the isolation of each XET activity attempted [various $\left(\mathrm{NH}_{4}\right)_{2} \mathrm{SO}_{4}$ cuts from extracts of cauliflower florets and mung bean seedlings], in pure form as judged by SDS/PAGE.

Key words: hemicellulose, oligosaccharide, plant cell wall, transglycosylation.

\section{INTRODUCTION}

Xyloglucan endotransglycosylases (XETs) are a family of cellwall enzymes with proposed roles in the assembly [1] and modification [2] of the xyloglucan-cellulose network. They act by cleaving a donor xyloglucan somewhere along its length, and by joining the newly formed potentially reducing end to the nonreducing end of an acceptor xyloglucan or xyloglucan-derived oligosaccharide [3-5]. Some XETs can also hydrolyse xyloglucan [6].

High XET activity has been correlated with regions of tissue extension in many plants, including pea stems [7], maize roots [8], barley leaves [9] and Arabidopsis stems [10]. Production of XET mRNA correlates with elongation in Arabidopsis stems [11] and also with elongation in response to growth-promoting treatments with auxins [12], gibberellins [11] and brassinosteroids [13]. Increased levels of XET also correlate with fruit softening in kiwi [14] and tomato [15] and with the mobilization of seed reserves in nasturtium [6]. Flooding-induced formation of aerenchyma in maize roots is closely linked to expression of an XET-like protein $[16,17]$. Thus XETs appear to participate in several diverse aspects of plant growth and development.

Crude plant extracts contain numerous isoforms of XET differing in isoelectric point, as revealed by zymogram techniques $[18,19]$, and the Arabidopsis genome contains at least 10 XETrelated (XTR) sequences [5,21]. Amino acid sequences predicted from $X T R$ DNA sequences fall into three groups [20]. Group III, which includes the nasturtium seed XET, is the only group that can hydrolyse xyloglucan $[6,21]$ and that shows a preference for a non-fucosylated donor [10]. One member of group II, TCH4, has been studied enzymologically [22]. However, nothing is known of the enzymological differences between groups I and II, which are classified solely on sequence similarity. Such differences could potentially include preferences for mid-chain or nearterminal cleavage of the donor substrate, for substrates with different chain-lengths or composition (e.g. degree of galac- tosylation, fucosylation or acetylation), and for $\mathrm{pH}$ and temperature. Individual $X T R$ genes differ in the spatial and temporal patterns of their expression, probably reflecting different biological roles [20].

Progress in characterizing individual XET isoforms, and thus in elucidating their physiological significance, would be greatly assisted by the availability of a simple and effective purification scheme. Previous purification techniques have relied on empirical combinations of anion-exchange, cation-exchange, hydrophobicinteraction and gel-permeation chromatography (GPC) $[23,24]$. Here we present a novel purification technique that exploits the stable association formed between XET and its donor substrate [25] and provides a simple and generally applicable method for purifying XETs from plant tissues.

\section{MATERIALS AND METHODS}

\section{Materials}

Xyloglucan can be prepared from tamarind flour [23] and digested to oligosaccharides with cellulase [18]. We obtained tamarind xyloglucan and a mixture of tamarind xyloglucan-derived oligosaccharides (principally XLLG, XXLG and XXXG; see below) as generous gifts of Mr. K. Yamatoya, Dainippon Pharmaceutical Co., Osaka, Japan. XLLG has the structure:

$$
\begin{gathered}
\beta \text {-Gal }{ }^{*}-(1 \rightarrow 2)-\alpha \text {-Xyl- }(1 \rightarrow 6) \\
\alpha \text {-Xyl- }(1 \rightarrow 6)-\beta \text {-Glc- }(1 \rightarrow 4)-\beta \text {-Glc- }(1 \rightarrow 4)-\beta \text {-Glc- }(1 \rightarrow 4)- \\
\beta \text {-Gal- }(1 \rightarrow 2)-\alpha-X y l-(1 \rightarrow 6)
\end{gathered}
$$

XXLG lacks the Gal residue marked (*), and XXXG lacks both Gal residues. $\left[1-{ }^{3} \mathrm{H}\right] \mathrm{XLLGol}$, in which the reducing terminal Glc moiety of XLLG is replaced by $\left[{ }^{3} \mathrm{H}\right]$ glucitol, was prepared as described previously [26].

Abbreviations used: XET, xyloglucan endotransglycosylase; GPC, gel-permeation chromatography; $V_{0}$, void volume; $V_{t}$, included volume; XTR, XET-related.

1 To whom correspondence should be addressed (e-mail S.Fry@Ed.Ac.UK). 


\section{Enzyme extraction}

Mung bean seedlings and cauliflower florets (400 g) were homogenized in ice-cold buffer A [600 ml; $350 \mathrm{mM}$ succinate $\left(\mathrm{Na}^{+}\right)$/ $16.7 \mathrm{mM} \mathrm{CaCl} / 1.67 \mathrm{mM}$ dithiothreitol ( $\mathrm{pH} 5.5)$ ], using an AtoMix blender. The homogenate was then left at $4{ }^{\circ} \mathrm{C}$ for $2 \mathrm{~h}$ with occasional mixing, strained through muslin and centrifuged at $2500 \mathrm{~g}$ for $30 \mathrm{~min}$.

\section{Ammonium sulphate precipitation}

Proteins were precipitated from $100 \mathrm{ml}$ of crude extract in a stepwise manner at $4{ }^{\circ} \mathrm{C}$ with increasing saturation of $\left(\mathrm{NH}_{4}\right)_{2} \mathrm{SO}_{4}$. The precipitates were collected by centrifugation at $12000 \mathrm{~g}$ for $10 \mathrm{~min}$ at $4{ }^{\circ} \mathrm{C}$, re-dissolved in $3 \mathrm{ml}$ of $60 \%$ buffer $\mathrm{A}$ and flashfrozen in liquid $\mathrm{N}_{2}$ in $0.5 \mathrm{ml}$ aliquots.

\section{Assay of XET activity}

XET activity was assayed using an adaptation of the method of [2]. Protein solution ( $10 \mu \mathrm{l}$ in $60 \%$ buffer A) was added to $20 \mu 1$ of an assay mixture containing $0.67 \%(\mathrm{w} / \mathrm{v})$ tamarind xyloglucan and $250 \mu \mathrm{M}\left[{ }^{3} \mathrm{H}\right]$ XLLGol (approximately $320 \mathrm{kBq} / \mu \mathrm{mol}$ ) in $60 \%$ buffer $\mathrm{A}$. The reaction was allowed to run for $40 \mathrm{~min}$ before being quenched with $20 \mu \mathrm{l}$ of $50 \%$ formic acid; the products were air-dried on Whatman 3MM paper and washed in running water overnight. The paper was then re-dried and the bound $\left[{ }^{3} \mathrm{H}\right]$ xyloglucan assayed using OptiScint HiSafe scintillation fluid (Wallac, Milton Keynes, Bucks, U.K.). XET activity is expressed in katals ( $1 \mathrm{~kat}=1 \mathrm{~mol}$ of product per s) per $30 \mu 1$ assay.

\section{Assay of xyloglucan}

Xyloglucan was assayed by the method described in [24]. To $200 \mu \mathrm{l}$ of sample (typically containing xyloglucan at $0.02-1.0$ $\mathrm{mg} / \mathrm{ml}), 1 \mathrm{ml}$ of $20 \% \mathrm{Na}_{2} \mathrm{SO}_{4}$ was added, followed by $200 \mu \mathrm{l}$ of a solution containing $0.5 \% \quad \mathrm{I}_{2}$ and $1 \%$ KI. The $A_{620}$ was measured within 10 min.

\section{GPC}

Bio-Gel A- $0.5 \mathrm{M}$ columns (bed volume $\approx 90 \mathrm{ml}$, internal diameter $2.5 \mathrm{ml}$ ) were run at $\approx 0.5 \mathrm{ml} / \mathrm{min}$ at $4{ }^{\circ} \mathrm{C}$. Columns were equilibrated in buffer $\mathrm{B}\left[100 \mathrm{mM}\right.$ succinate $\left(\mathrm{Na}^{+}\right)(\mathrm{pH} 5.5) / 10 \mathrm{mM}$ $\mathrm{CaCl}_{2}$ ] and either $1 \mathrm{M} \mathrm{NaCl}$ or $10 \%$ glycerol. Fractions of $1.5 \mathrm{ml}$ were collected and assayed for XET activity.

\section{Polyacrylamide gels}

Proteins were separated by SDS/PAGE in a $14 \%(w / v)$ gel [27]. Samples were solubilized in sample buffer to give a final concentration of $5 \%$ SDS $/ 10 \%$ glycerol $/ 0.02 \%$ Bromophenol Blue/62.5 mM Tris/ $\mathrm{HCl}$ ( $\mathrm{pH} 6.8) / 50 \mathrm{mM}$ iodoacetamide [28] and boiled for $5 \mathrm{~min}$ before loading. Proteins were visualized using a silver stain.

\section{Optimized purification method}

A sample $(0.5 \mathrm{ml})$ containing XET activity was incubated in $0.2 \%(\mathrm{w} / \mathrm{v})$ tamarind xyloglucan for $30 \mathrm{~min}$ at $4{ }^{\circ} \mathrm{C}$ in buffer $\mathrm{B}$. The solution was then spiked with Blue Dextran $(0.8 \mathrm{mg})$ and subjected to GPC in buffer $\mathrm{B}$ containing $1 \mathrm{M} \mathrm{NaCl}$. The void fractions (blue) were pooled, concentrated by ultrafiltration using dialysis tubing and poly(ethylene glycol) 20000, and fractionated on a second GPC column in buffer B containing $10 \%$ glycerol and $210 \mu \mathrm{M}$ xyloglucan oligosaccharides.

\section{RESULTS}

\section{Ammonium sulphate precipitation of XET activities from crude extracts}

Step-wise addition of $\left(\mathrm{NH}_{4}\right)_{2} \mathrm{SO}_{4}$ to crude extracts of cauliflower florets and mung bean seedlings revealed distinct precipitable XET activities (Figure 1). These may represent distinct isoforms of XET and so were treated separately.

\section{Xyloglucan-dependent shift in elution pattern of XET from GPC columns}

XET activity in a crude extract of cauliflower florets eluted near the totally included volume $\left(V_{\mathrm{t}}\right)$ on Bio-Gel A- $0.5 \mathrm{M}$ (fractionation range $10-500 \mathrm{kDa}$; Figure 2, O). The peak of activity extended past the $V_{\mathrm{t}}$ and was broader than the peak of internal marker $\left[{ }^{3} \mathrm{H}\right]$ glucose (Figure $2,-{ }^{-}-$). This suggests a slight affinity of XET for the agarose of the column. Similar behaviour on GPC has been observed for a xyloglucan hydrolase/ endotransglycosylase [23] but is not sufficient for enzyme purification, as shown by the protein profile (Figure $2,-\cdot-$ ).

XETs form remarkably long-lived, probably covalent, complexes with xyloglucan [25] and we have isolated such complexes as a step towards enzyme purification. After incubation of the crude extract with $0.2 \%$ tamarind xyloglucan $(\approx 1 \mathrm{MDa})$, the activity eluted almost solely in the void volume $\left(V_{0}\right.$; Figure 2 , $\boldsymbol{\square}$ ), indicating that a stable, high-molecular-mass complex had been formed. The complex remained in $V_{0}$ when the eluent contained $2 \mathrm{M} \mathrm{NaCl}, 2 \mathrm{M}$ guanidinium hydrochloride or $2 \mathrm{M}$ urea (results not shown), as expected for a covalent XETxyloglucan bond.

SDS/PAGE of the $V_{0}$ material revealed numerous bands; fewer bands were present when the eluent contained $\mathrm{NaCl}$

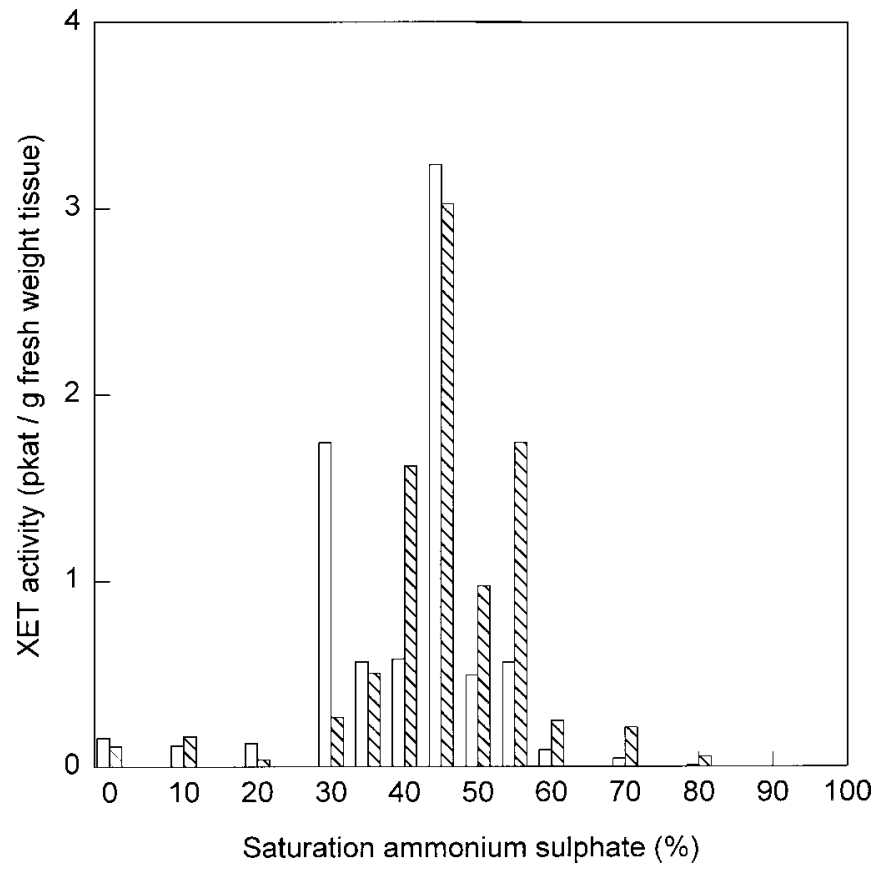

Figure 1 Ammonium sulphate fractionation of XET activity

Crude extracts of cauliflower florets (open bars) and mung bean seedlings (hatched bars) were fractionated by step-wise addition of $\left(\mathrm{NH}_{4}\right)_{2} \mathrm{SO}_{4}$ at $4{ }^{\circ} \mathrm{C}$. Each pellet was resuspended in buffer $\mathrm{B}$ and assayed for XET activity. 


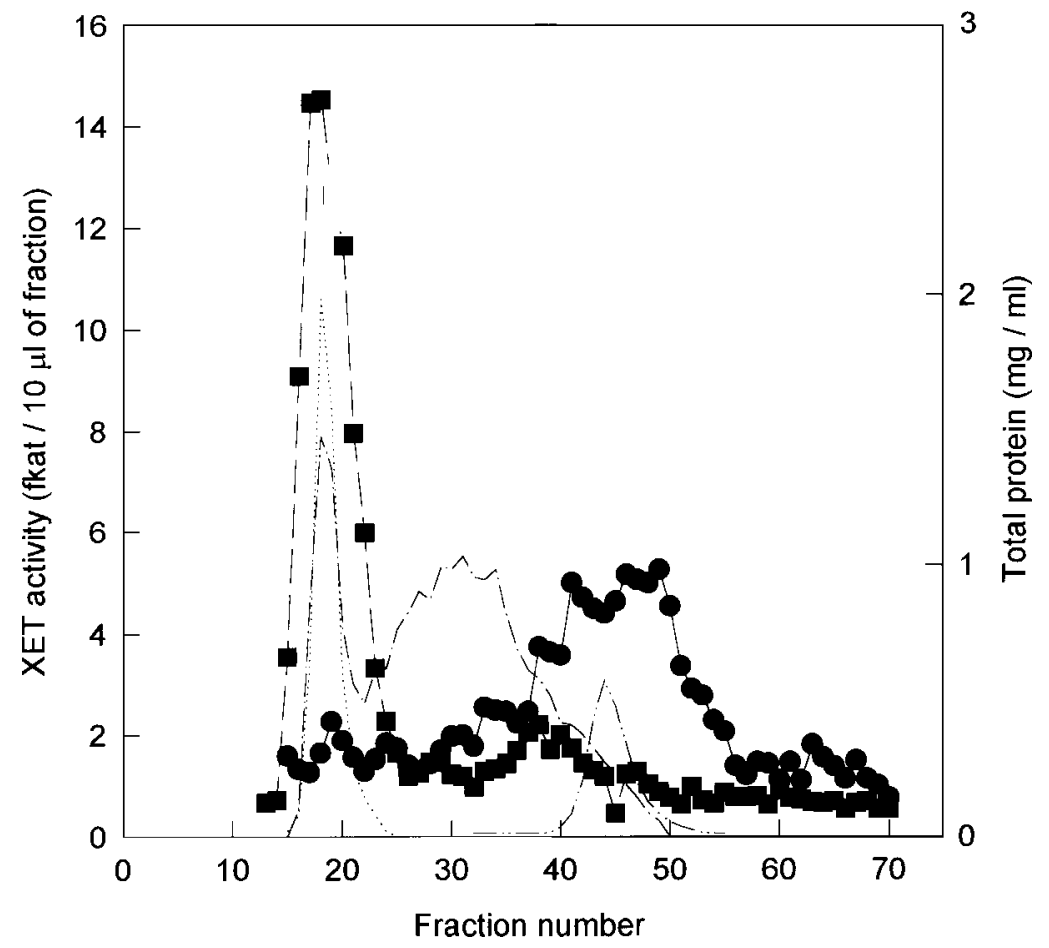

Figure 2 GPC of crude cauliflower XET in the presence and absence of xyloglucan

Cauliflower extract was chromatographed on Bio-Gel A-0.5M in the absence of xyloglucan $(\mathbf{O})$, and after a pre-incubation in $0.2 \%(\mathrm{w} / \mathrm{v})$ tamarind xyloglucan for 30 min at $4{ }^{\circ} \mathrm{C}(\boldsymbol{\square})$. The $V_{0}$ was determined using $2 \mathrm{MDa}$ Blue Dextran $(\cdots \cdots)$ and the $V_{\mathrm{t}}$ with $\left[{ }^{3} \mathrm{H}\right]$ glucose $(-\cdots+\cdot)$, both on an arbitrary $y$-axis scale. Protein concentration $\left(-\cdot{ }^{-\cdot}-\right)$ was estimated with the Bio-Rad dye-binding protein assay: measurements are shown for the ' $\mathbf{\square}$ ' data; a very similar profile (results not shown) was obtained for the ' $\mathbf{O}$ ' data.

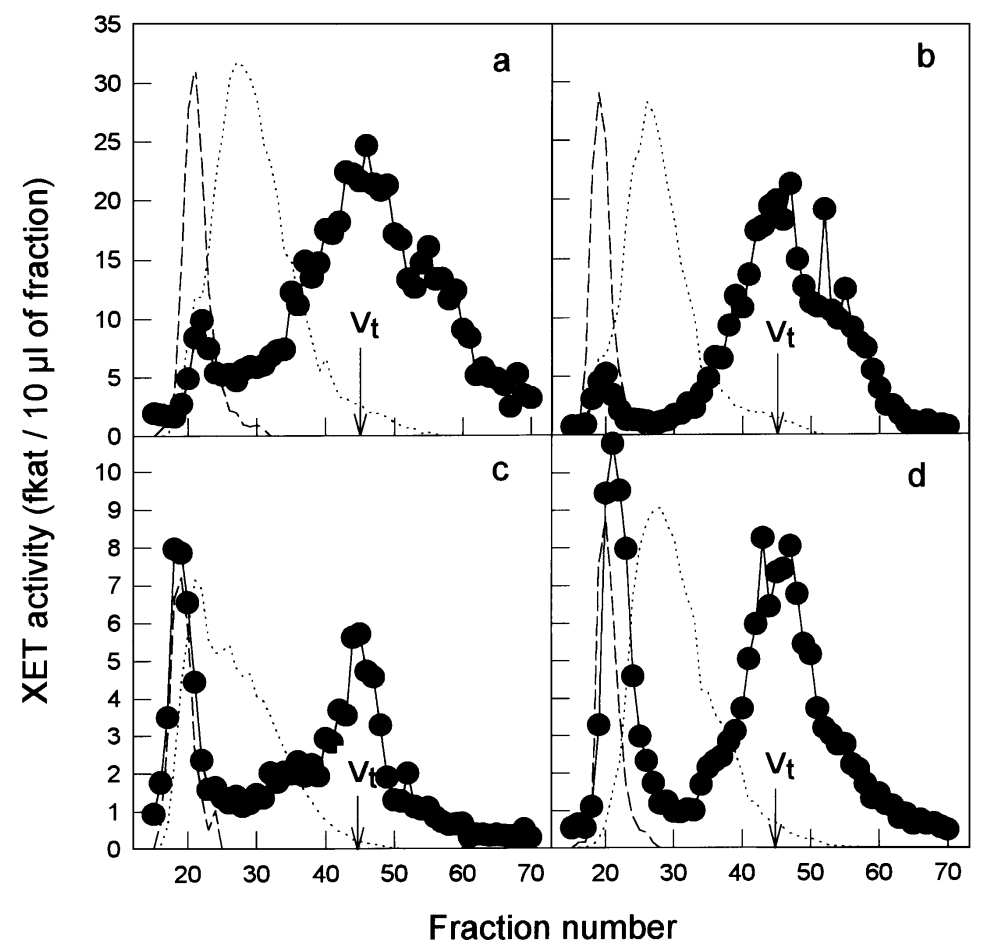

Figure 3 Disruption of XET-xyloglucan complexes in the presence of xyloglucan-derived oligosaccharides

$\left(\mathrm{NH}_{4}\right)_{2} \mathrm{SO}_{4}$-precipitated XET activities, complexed with xyloglucan as in Figure 2, were re-chromatographed in the presence of oligosaccharides. The graphs show XET activity $(-)$, the void marker Blue Dextran (- - ; on an arbitrary $y$-axis scale), the $V_{t}$ (arrows) and xyloglucan $(\cdots \cdots$, ; also on an arbitrary $y$-axis scale). The activities used were those precipitated from cauliflower extract by $45 \%$ saturated $\left(\mathrm{NH}_{4}\right)_{2} \mathrm{SO}_{4}$ (a), and from mung bean extract by $45 \%(\mathbf{b}), 35 \%$ (c) and $55 \%$ (d) saturated $\left(\mathrm{NH}_{4}\right)_{2} \mathrm{SO}_{4}$. 
Table 1 Typical yield and degree of purification of XET activity precipitated by $40-45 \%$ saturated $\left(\mathrm{NH}_{4}\right)_{2} \mathrm{SO}_{4}$

${ }^{*}$ This activity was assayed after dialysis to remove the oligosaccharides from the column eluate.

\begin{tabular}{|c|c|c|c|c|c|}
\hline Fraction & $\begin{array}{l}\text { Total volume } \\
\text { (ml) }\end{array}$ & $\begin{array}{l}\text { Protein quantity } \\
(\mathrm{mg})\end{array}$ & $\begin{array}{l}\text { Specific activity } \\
\text { (pkat/mg) }\end{array}$ & Fold purification & Recovery $(\%)$ \\
\hline$\left(\mathrm{NH}_{4}\right)_{2} \mathrm{SO}_{4}$ pellet & 1.00 & 31.2 & 17.0 & 1 & 100 \\
\hline Void from first Bio-Gel column & 8.25 & 8.75 & 25.6 & 1.51 & 42.2 \\
\hline Pure XET from second Bio-Gel column & 26.4 & 0.0124 & $3640^{*}$ & 214 & 8.51 \\
\hline
\end{tabular}

a

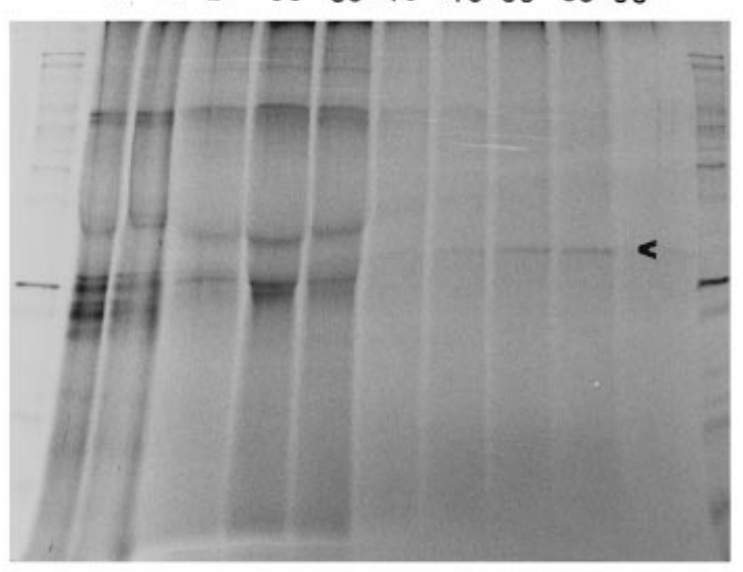

b $1922 \quad 26 \quad 30 \quad 35 \quad 40 \quad 45 \quad 50 \quad 55 \quad 60$

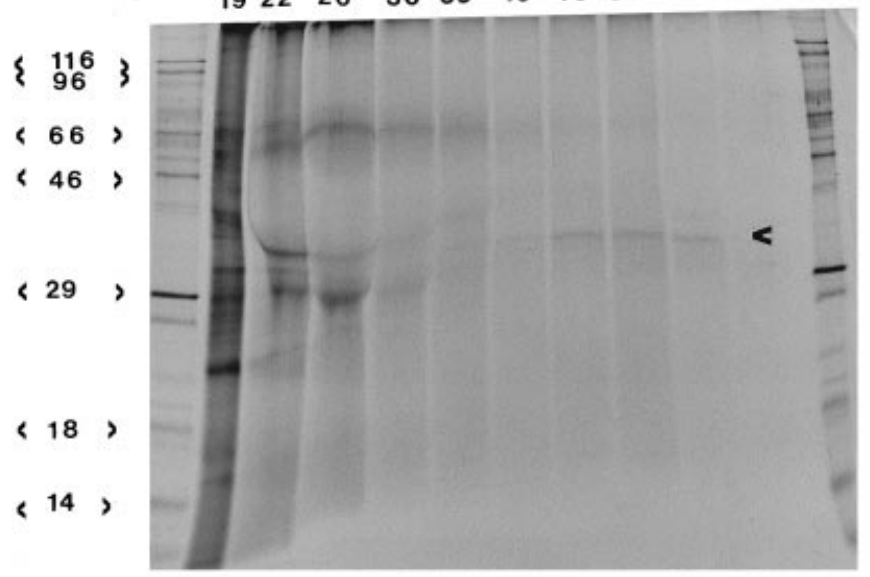

Figure 4 SDS/PAGE of the fractions shown in Figures $3 a(a)$ and $3 b(b)$

Lanes are labelled with GPC fraction numbers. Large arrowheads indicate the purified XETs; small arrowheads show marker proteins (in kDa).

(results not shown), which was therefore added in subsequent purification work.

\section{Purification of XET isoenzymes}

To purify the putative XET isoenzymes, we added xyloglucanderived oligosaccharides, which disrupted the XET-xyloglucan complex and shifted the activity back into the included volume.

$\left(\mathrm{NH}_{4}\right)_{2} \mathrm{SO}_{4}$-precipitated XET activity was mixed with xyloglucan and the complex was isolated by GPC as above. The void fractions were concentrated and re-chromatographed on Bio-Gel $\mathrm{A}-0.5 \mathrm{M}$ in the presence of $10 \%$ glycerol and $210 \mu \mathrm{M}$ xyloglucanderived oligosaccharides. (As the XETs were progressively purified, their activity became unstable; this problem could be minimized by addition of $10 \%$ glycerol.) During the running of this column, the oligosaccharides presumably acted as acceptors in an XET-catalysed transglycosylation reaction, allowing the XET to fall away from the xyloglucan and therefore to elute near the $V_{t}$, well resolved from the majority of the xyloglucan (Figure 3 ). The occurrence of the transglycosylation event is supported by the oligosaccharide-dependent partial degradation of the xyloglucan, shown by the shifting of the xyloglucan away from $V_{0}$ (Figure 3 ). This method was used successfully to purify all $\left(\mathrm{NH}_{4}\right)_{2} \mathrm{SO}_{4}$-precipitated XET samples tested (Figure 3).

The recovery of activity was typically $\approx 10 \%$, with $\approx 200$ fold purification (Table 1). This compares well with the $10.5 \%$ recovery and an apparent 9.5-fold purification reported by Edwards et al. [23] and the $24 \%$ recovery and 87 -fold purification reported by Nishitani and Tominaga [4], both using more complex and less generally applicable procedures. We have not critically tested the capacity of our method, but we assume that at least one active XET molecule would bind per xyloglucan chain, giving a capacity of $10 \mathrm{nmol}(\approx 0.3 \mathrm{mg})$ of enzyme per column run. It can also be assumed that only active enzyme molecules would be obtained by our method. In support of this idea, the specific activity of the XET purified from mung bean (3600 pkat/mg) was 400 times higher than that of an Arabidopsis XET purified from transgenic Escherichia coli [22].

SDS/PAGE of the GPC fractions of the major $\left(\mathrm{NH}_{4}\right)_{2} \mathrm{SO}_{4}-$ precipitable peak from cauliflower (Figure 3a) indicated that the $V_{0}$ (fractions 21-23) contained a large array of polypeptides (Figure 4a). Fractions 27-35 contained several polypeptides, presumably those that had been associated specifically with the xyloglucan and co-shifted with the xyloglucan from $V_{0}$. Fractions $45-55$ contained a single $\approx 32 \mathrm{kDa}$ polypeptide corresponding to a pure cauliflower XET. Similar results were obtained with mung bean (Figure 4b).

\section{DISCUSSION}

This paper reports a novel, general and simple method for purifying XET activities to homogeneity. Previously characterized XETs are $\approx 32 \mathrm{kDa}[4,6,29]$, and would therefore be expected to be totally included on Bio-Gel A- $0.5 \mathrm{M}$. However, on addition of xyloglucan ( $\sim 1 \mathrm{MDa})$, XET activity shifted to the void volume owing to the formation of a stable xyloglucan-XET 
complex [25]. Most proteins in a crude plant extract have molecular mass $<500 \mathrm{kDa}$ and do not bind xyloglucan; this step therefore achieves a substantial purification of the XET. Final purification was achieved by addition of oligosaccharides (XET acceptor substrates) to dissociate the complex. The XET activity now shifted back to near the totally included volume, as expected for a $32 \mathrm{kDa}$ protein, yielding a final product that appeared to be homogeneous by SDS/PAGE.

The method reported will be valuable for the purification of XET isoenzymes both from crude plant extracts and from transgenic expression systems. This will enable enzymological characterization of pure XET proteins and hence give insight into their biological roles.

We thank Dr. J. E. Thompson for constructive discussions and Mrs. J. G. Miller for excellent technical assistance. We thank the Biotechnology and Biological Sciences Research Council for financial support.

\section{REFERENCES}

1 Thompson, J. E., Smith, R. C. and Fry, S. C. (1997) Biochem. J. 327, 699-708

2 Fry, S. C., Smith, R. C., Renwick, K. F., Martin, D. J., Hodge, S. K. and Matthews, K. J. (1992) Biochem. J. 282, 821-828

3 Smith, R. C. and Fry, S. C. (1991) Biochem. J. 279, 529-535

4 Nishitani, K. and Tominaga, R. (1992) J. Biol. Chem. 267, 21058-21064

5 Nishitani, K. (1997) Int. Rev. Cytol. 173, 157-206

Received 6 October 1998/4 January 1999; accepted 17 February 1999
6 Fanutti, C., Gidley, M. J. and Reid, J. S. G. (1993) Plant J. 3, 691-700

7 Potter, I. and Fry, S. C. (1993) Plant Physiol. 103, 235-241

8 Pritchard, J., Hetherington, P. R., Fry, S. C. and Tomos, A. D. (1993) J. Exp. Bot. 44, $1281-1289$

9 Smith, R. C., Matthews, R., Schünmann, P. and Chandler, P. (1996) J. Exp. Bot. 47, 1395-1404

10 Rose, J. K. C., Brummell, D. A. and Bennett, A. B. (1996) Plant Physiol. 110 493-499

11 Aubert, D. and Herzog, M. (1996) Plant Sci. 121, 187-196

12 Xu, W., Purugganan, M. M., Polisensky, D. H., Antosiewicz, D. M., Fry, S. C. and Braam, J. (1995) Plant Cell 7, 1555-1567

13 Zurek, D. and Clouse, S. (1994) Plant Physiol. 104, 161-170

14 Redgwell, R. J. and Fry, S. C. (1993) Plant Physiol. 103, 1399-1406

15 Maclachlan, G. and Brady, C. (1994) Plant Physiol. 105, 965-974

16 Saab, I. N. and Sachs, M. M. (1995) Plant Physiol. 108, 439-440

17 Saab, I. N. and Sachs, M. M. (1996) Plant Physiol. 112, 385-391

18 Fry, S. C. (1997) Plant J. 11, 1141-1150

19 lannetta, P. P. M. and Fry, S. C. (1999) Phytochem. Anal., in the press

20 Xu, W., Campbell, P., Vargheese, A. K. and Braam, J. (1996) Plant J. 9, 879-889

21 Fanutti, C., Gidley, M. J. and Reid, J. S. G. (1996) Planta 200, 221-228

22 Purugganan, M. M., Braam, J. and Fry, S. C. (1997) Plant Physiol. 115, 181-190

23 Edwards, M., Dea, I., Bulpin, P. and Reid, J. (1986) J. Biol. Chem. 261, 9489-9494

24 Sulová, Z., Lednická, M. and Farkaš, V. (1995) Anal. Biochem. 229, 80-85

25 Sulová, Z., Takáčová, M., Steele, N. M., Fry, S. C. and Farkaš, V. (1998) Biochem. J. 330, $1475-1480$

26 Hetherington, P. R. and Fry, S. C. (1993) Plant Physiol. 103, 987-992

27 Laemmli, U.K. (1970) Nature (London) 227, 680-685

28 Beis, A. and Lazou, A. (1990) Anal. Biochem. 190, 57-59

29 de Silva, J., Jarman, C. D., Arrowsmith, D. A., Stronach, M. S., Chengappa, S., Sidebottom, C. and Reid, J. S. G. (1993) Plant J. 3, 701-711 